Check for updates

Cite this: RSC Adv., 2017, 7, 23890

Received 23rd February 2017 Accepted 19th April 2017

DOI: 10.1039/c7ra02264f

rsc.li/rsc-advances

\section{Directly grown carbon nanotube based hybrid electrodes with enhanced thermo-cell performances $\uparrow$}

\author{
Fang Zhao, Weijin Qian, (D)* Mengjie Li, Wei Li, Lihong Chen, Fengying Zhong, \\ Weijun Huang and Changkun Dong*
}

\begin{abstract}
Hybrid electrodes exhibit intriguing properties due to the synergetic effect of different components that are propitious for the practical applications of thermo-cells (TECS). In this study, Ag-carbon nanotube (CNT) hybrid electrodes were prepared using two simple and effective steps, involving the direct growth of CNTs on stainless steel substrates without any external catalyst, followed by decorating the CNTs with Ag nanoparticles. Ag-CNT electrodes were characterized via scanning electron microscopy, X-ray diffraction, Raman spectroscopy, and X-ray photoelectron spectroscopy and were applied in TECs for the first time. The TEC performances of the Ag-CNT electrodes were significantly enhanced compared to that of the pristine CNT electrode due to their better conductivity and thermal conductivity, as well as more activation sites. The results show that the construction of $\mathrm{Ag}-\mathrm{CNT}$ hybrid electrodes can effectively improve the TEC performances of CNT electrodes, which is promising for heat energy harvesting by CNT-based electrodes.
\end{abstract}

\section{Introduction}

With the decrease in fossil fuel resources, research interests have been focused on the development of sustainable energy, such as wind, geothermal, hydro and biomass. ${ }^{1}$ Among the sustainable energy sources, low-grade heat (usually temperatures below $130{ }^{\circ} \mathrm{C}$ ) has attracted great attention due to its advantage of electricity production without air pollution. ${ }^{2}$ More importantly, there is plenty of low grade waste heat in many fields, e.g. waste heat from industry, exhaust gases of vehicles, geothermal energy, and heat from storage systems..$^{2,3}$

Thermo-cell (TEC) technology is attracting more and more interest in energy harvesting due to its simple design, direct energy conversion from heat to electricity, capability of continuous operation, and low cost. ${ }^{2}$ Compared with traditional TEC materials, ${ }^{4}$ e.g. Pt or Pd, carbon nanotubes (CNTs) are considered promising alternatives as TEC electrodes due to their high thermal and electrical conductivities, high specific surface areas, and quick electron transfer ability. ${ }^{2,3,5-10}$ However, it is still difficult to obtain high relative conversion efficiency with a single component based on carbon nanomaterials, which is crucial for the practical applications of CNT-based TECs. Recently, CNT-based hybrid electrodes were used as TEC electrodes with higher output power and relative energy

Institute of Mirco-Nano Structure \& Optoelectronics, Wenzhou University, Wenzhou 325035, P. R. China. E-mail: weijinqian@wzu.edu.cn; dck@wzu.edu.cn; Fax: +86 57786689011; Tel: +86 57786689067

$\dagger$ Electronic supplementary information (ESI) available. See DOI: 10.1039/c7ra02264f conversation efficiency due to the synergetic effects of different materials. Romano et al. reported that the TEC performances of single-walled carbon nanotube-reduced graphene oxide hybrid electrodes were improved significantly due to an enhanced mass transport property. ${ }^{7}$ Im et al. reported that decorating CNTs with Pt nanoparticles (NPs) could result in much higher conversation efficiency in comparison with pristine CNTs due to faster kinetics and larger electroactive sites. ${ }^{\mathbf{1 0}}$

The direct growth of CNTs on metal substrates could enhance the adherence between CNT electrodes and metal substrates, which might be beneficial for electron and thermal transfer in CNT electrodes. ${ }^{\mathbf{1 1 - 1 4}}$ In addition, the construction of Ag-CNT hybrid electrodes could enhance the conductivity, thermal conductivity, and electrochemical activity of pristine CNT electrodes. ${ }^{15-17}$ In comparison with the Pt-CNT and AuCNT hybrids, the Ag-CNT hybrid has higher conductivity and thermal conductivity, ${ }^{18}$ which enhance the performances of thermo-cells. ${ }^{2,4,5}$ In addition, noble metal NPs such as Pt and Au were coated on the surfaces of CNTs via a reduction reaction, ${ }^{\mathbf{1 8}}$ whereas Ag NPs were decorated on CNTs via the electrophoretic deposition method, which is simple, easy to control, and low cost. ${ }^{19}$ In this work, Ag-CNT hybrid electrodes are prepared using two simple and effective steps, which involve the direct growth of CNTs on stainless steel substrates without any external catalyst, followed by decorating the CNTs with Ag NPs, and the as-obtained electrodes are applied in TECs. In comparison with the pristine CNT electrode, the TEC performances of the Ag-CNT hybrid electrodes are much improved, which suggests a promising approach to develop practical CNTbased hybrid electrodes. 


\section{Experimental}

Direct growth of CNTs on stainless steel (SS) substrates

First, SS substrates were pretreated with acetone, alcohol, and deionized water for $15 \mathrm{~min}$, respectively. Subsequently, the SS substrates were anodized with an oxalic acid solution $(0.3 \mathrm{~mol}$ $\mathrm{L}^{-1}$ ), followed by CVD growth of CNTs directly on the substrates using $\mathrm{C}_{2} \mathrm{H}_{2}(20 \mathrm{sccm})$ as the carbon source and an Ar flow (200 $\mathrm{sccm})$ as the carrier gas at $750{ }^{\circ} \mathrm{C}$.

\section{Synthesis of Ag-CNT hybrid electrodes}

First, $\mathrm{AgNO}_{3}$ (99.5\%, Aladdin) was dispersed in ethanol and sonicated for about 1 hour to form a homogeneous solution. During electrophoretic deposition (EPD), the as-prepared CNT electrode (working electrode) and stainless steel sheet (counter electrode) were immersed in the $\mathrm{AgNO}_{3}$ solution $\left(1 \times 10^{-5} \mathrm{~g}\right.$ $\mathrm{L}^{-1}$ ) at a distance of $1 \mathrm{~cm}$ apart. After EPD, the products were annealed at $400{ }^{\circ} \mathrm{C}$ under the protection of Ar to finally obtain the Ag-CNT hybrid electrode. The TEC performances of the AgCNT hybrids were optimized by changing the deposition time. The as-prepared hybrid electrodes are denoted as Ag-CNTs- $x$, where $x$ represents the deposition time.

\section{Characterization}

The morphologies of the electrodes were observed by scanning electron microscopy (SEM; JEOL JSM-7100F). The species components of the as-prepared hybrid film were analyzed via $\mathrm{X}$ ray diffraction (XRD; GmbH SMART APEX), Raman spectroscopy
(Renishaw Invia Raman Microscope) and X-ray photoelectron spectroscopy (XPS; PHI 5000 VersaProbe).

\section{TEC testing}

The TEC performances of the CNTs and Ag-CNTs hybrid electrodes were tested in a cup-shaped device (see SI-1 in ESI $\dagger$ ) using a potassium ferri/ferrocyanide aqueous solution as the electrolyte $\left(0.4 \mathrm{~mol} \mathrm{~L}^{-1}\right)$. The distance between the two test electrodes was $4 \mathrm{~cm}$ and the electrode area was $0.36 \mathrm{~cm}^{2}$. The temperatures of the cold and hot sides were controlled using ice water and heating tape, respectively. The temperature readings of the two sides were both obtained using OMEGA thermocouple probes. The cell potentials and output currents were measured using a KEITHLEY 2440 multimeter.

\section{Results and discussion}

The structural characterizations of the samples are shown in Fig. 1. From the SEM images, the diameters of the pristine CNTs grown on the SS substrate are typically in the range of 50$100 \mathrm{~nm}$ (Fig. 1a). After the EPD process, the CNT surface was coated with $\mathrm{Ag}$ particles with sizes in the range of 5-40 nm (Fig. 1b). As shown in Fig. 1c, for the pristine CNTs, XRD characterization indicates that the peak at $26.4^{\circ}$ corresponds to the (002) plane of CNTs. ${ }^{20}$ The other four peaks could be attributed to the (111), (110), (200) and (220) crystallographic planes of SS. ${ }^{21}$ For the Ag-CNTs, besides the above-mentioned five peaks, the metal $\mathrm{Ag}$ (111) peak appeared at $38.2^{\circ} .^{15}$
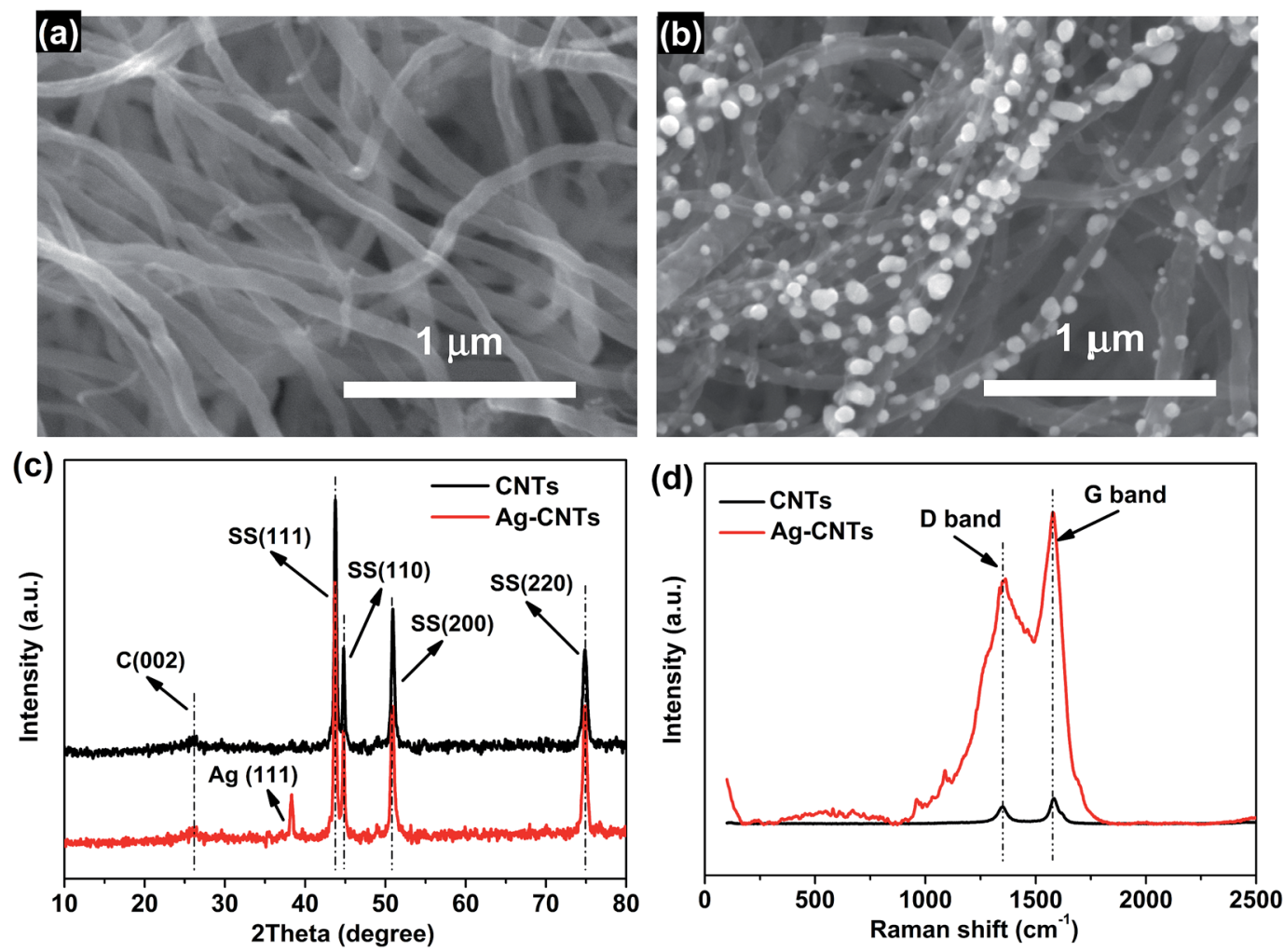

Fig. 1 SEM images of (a) pristine CNTs and (b) Ag-CNTs hybrid nanostructures, (c) XRD results and (d) Raman spectra of the products. 
Raman spectroscopy was applied to detect if any charge transfer occurred between the Ag NPs and CNTs. ${ }^{22}$ As shown in Fig. 1d, both the pristine CNTs and Ag-CNTs show two Raman peaks with the same values, i.e. D-band at $1353 \mathrm{~cm}^{-1}$ and G-band at $1580 \mathrm{~cm}^{-1}$, which suggests that no obvious charge transfer took place between the Ag NPs and CNTs. ${ }^{22}$ As is well known, the Dband is related to the defects or vacancies in CNTs and comes from the amorphous or disordered carbon structures in CNTs, whereas the G-band is mainly related to the degree of graphite in the CNTs. ${ }^{22}$ Generally, if the intensity ratio of the G-band to D-band is high, the CNTs are considered to have good conductivity. ${ }^{23,24}$ Therefore, in the present study, in comparison with the pristine CNTs, the higher value of $I_{\mathrm{G}} / I_{\mathrm{D}}$ of the Ag-CNTs indicates that the decoration of CNTs with Ag NPs should improve the conductivity of the pristine CNTs.

XPS was carried out for further analysis of the Ag-CNTs samples, as displayed in Fig. 2 (see SI-2 in ESI $\dagger$ ). As shown in Fig. 2a, the characteristic signals of $\mathrm{C}$ and $\mathrm{Ag}$ were observed in the Ag-CNTs-10 sample, where the $O$ signals were from the surface oxidation of the product and the signals of $\mathrm{Fe}$ and $\mathrm{Cr}$ originated from the SS substrate. ${ }^{13}$ For the $\mathrm{C}$ 1s spectra (Fig. 2b), a major signal from $\mathrm{sp}^{2}$ carbon was detected at $284.6 \mathrm{eV}$, and two minor signals from $\mathrm{C}-\mathrm{O}$ and $\mathrm{C}=\mathrm{O}$ bonds were observed at 285.8 and $288.8 \mathrm{eV}$, respectively. ${ }^{25}$ For the $\mathrm{O}$ 1s spectra (Fig. 2c), four peaks from $\mathrm{O}-\mathrm{Fe}, \mathrm{O}-\mathrm{Cr}, \mathrm{O}=\mathrm{C}$ and $\mathrm{O}-\mathrm{C}$ bonds appeared at
529.8, 530.6, 531.7 and 533.3 eV, respectively (see SI-3 in ESI $\dagger$ ). ${ }^{13,26}$ As shown in Fig. 2d, the binding energies (BE) of $\mathrm{Ag}$ $3 \mathrm{~d}_{3 / 2}$ and $\mathrm{Ag} 3 \mathrm{~d}_{5 / 2}$ were detected at $374.4 \mathrm{eV}$ and $368.4 \mathrm{eV}$, respectively, which is in agreement with that for metallic silver. ${ }^{27}$

The unchanged $\mathrm{BE}$ for $\mathrm{Ag}$ in the $\mathrm{Ag}-\mathrm{CNT}$ hybrid sample indicates that the charge transfer between the $\mathrm{Ag}$ and CNT species is negligible, which is in agreement with the Raman result. Three types of interactions exist between Ag and CNTs in the Ag-CNT hybrids in previous reports, i.e. covalent bonding, van der Waals forces and electrostatic interaction. ${ }^{15,28,29}$ According to the XPS analysis, we do not believe that covalent bonding exists in the Ag-CNT hybrids because there is no obvious charge transfer between $\mathrm{Ag}$ and CNTs. In addition, electrostatic interaction does not exist in the Ag-CNT hybrids due to the existence of uncharged CNTs. Therefore, we assume that the mutual relations between $\mathrm{Ag}$ and CNTs are van der Waals forces since similar cases can be found in the literature. ${ }^{15}$

According to previous experimental results, Ag NPs were successfully coated on CNTs. Therefore, superior TEC performances could be expected for the hybrid electrodes due to their enhanced conductivity and more activation sites. ${ }^{16,17,30}$ In this work, the TEC properties were tested using a cup-shaped TEC and $0.4 \mathrm{M}$ potassium ferro-ferricyanide aqueous solution was employed as the redox couple due to its high Seebeck
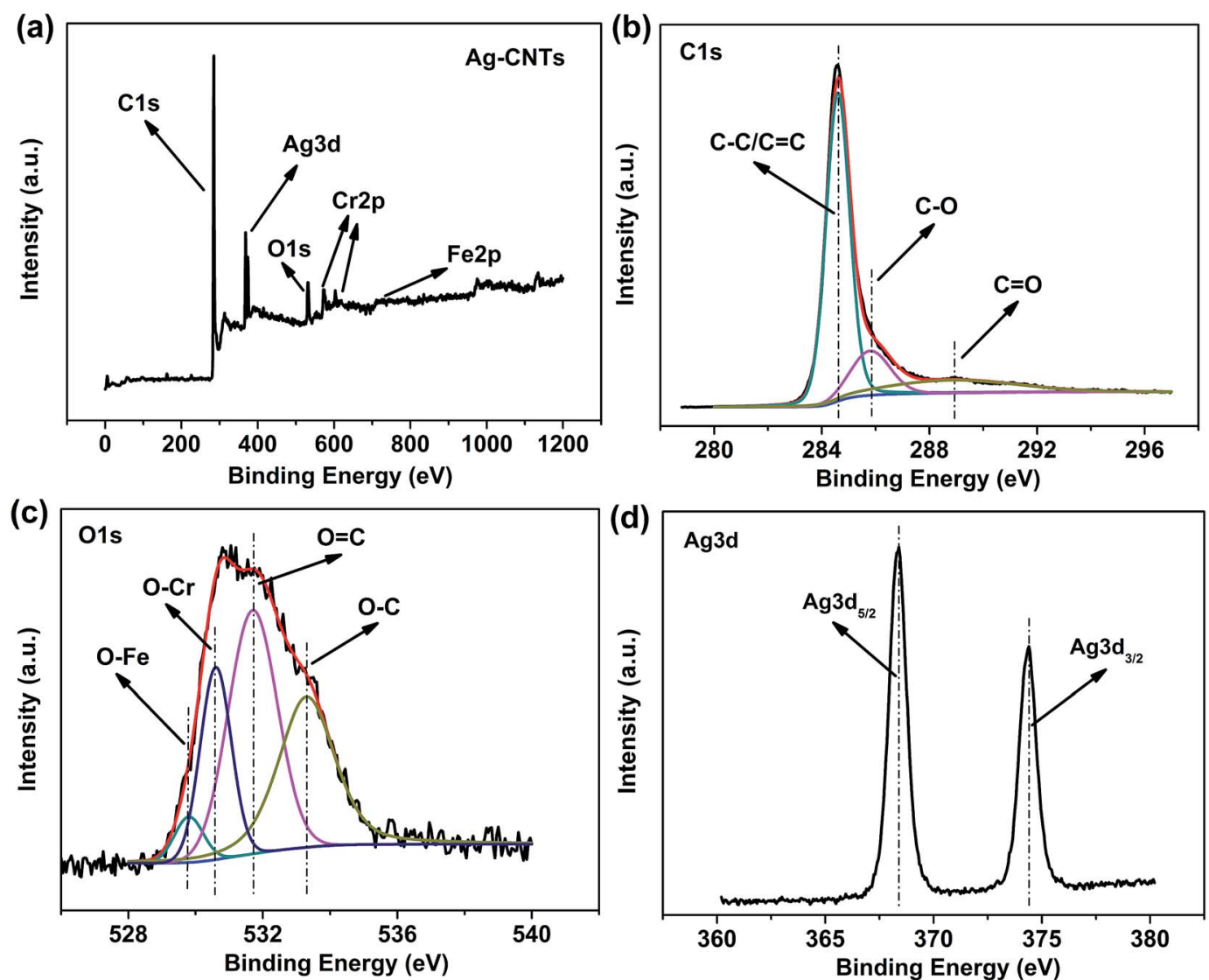

Fig. 2 XPS spectra of the Ag-CNTs-10 sample. (a) Survey; (b) C 1s; (c) O 1s and (d) Ag 3d. Note: the peak for C $1 \mathrm{~s}$ at 284.6 eV is used for calibration. 

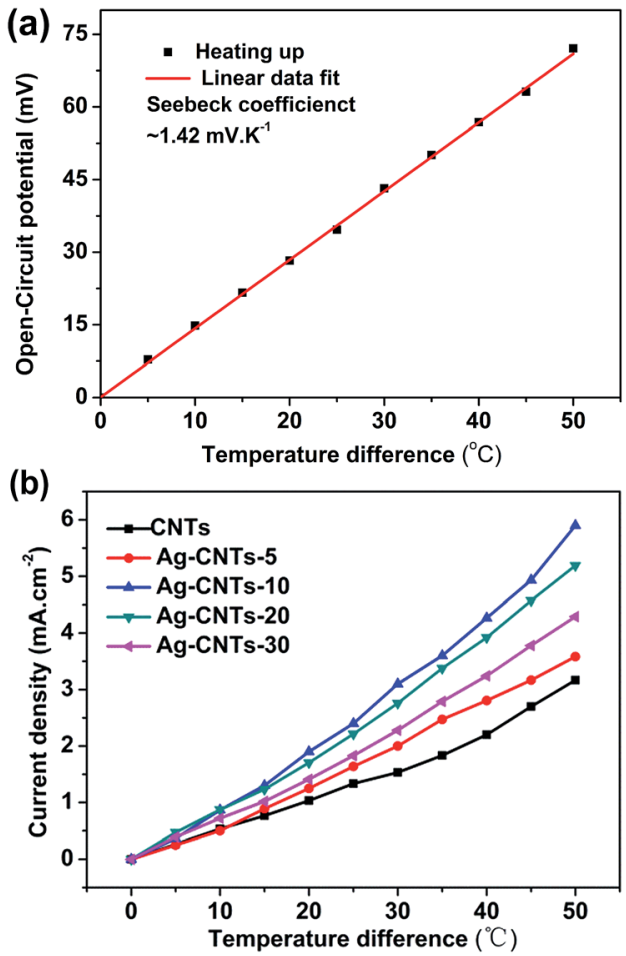

Fig. 3 (a) Voltage versus temperature difference for $0.4 \mathrm{M}$ ferro/ ferricyanide redox couple and (b) current density versus temperature difference between the CNTs electrode and the Ag-CNTs hybrid electrodes. coefficient. $^{2,7}$ As shown in Fig. 3a, the Seebeck coefficient was found to be $\sim 1.42 \mathrm{mV} \mathrm{K}^{-1}$ by linear fitting of the data, which is in agreement with the previous reports. ${ }^{2}$ Fig. $3 \mathrm{~b}$ shows that the current densities $\left(J_{\mathrm{SC}}\right)$ improved with an increase in the temperature differences for the pristine CNTs electrode and the $\mathrm{Ag}-\mathrm{CNTs}$ hybrid electrodes, and the $J_{\mathrm{SC}}$ of the Ag-CNTs electrodes was much higher than that of the pristine CNTs electrode at the same temperature difference due to their better conductivity and thermal conductivity (see SI-4 in ESI $\dagger$ ). In the case of the Ag-CNTs hybrid electrodes, with an increase in the content of $\mathrm{Ag}$ NPs, the conductivity and thermal conductivity of the hybrids were enhanced, but the specific surface area of the AgCNTs hybrid electrode gradually decreased due to the increased Ag NP density, ${ }^{30,31}$ thus the optimal TEC performance was obtained with the Ag-CNT-10 hybrid electrode.

The output power of TECs is determined by the cell potential $(U)$ and output current $(I)$. The output current could be obtained by changing the values of the external load resistance $\left(R_{\text {ext }}\right)$ in series with the cell according to the equation: $U=V_{\mathrm{oc}}-I \times r$, where $V_{\text {oc }}$ is the open-circuit potential depending on the temperature difference, ${ }^{32}$ and $r$ is the internal resistance of the TEC, which is mainly determined by the configuration of the TEC. ${ }^{3,432}$ Therefore, an approximately linear relationship between $U$ and $I$ can be found. The output power $(P)$ is then obtained using the following equations: $P=U I=\left(V_{\mathrm{oc}}-I \times r\right) I=V_{\mathrm{oc}} \times I-I^{2} \times r$, thus the $P-I$ curve shows an approximately quadratic relationship. The discharge characteristics curves of the cell are shown in
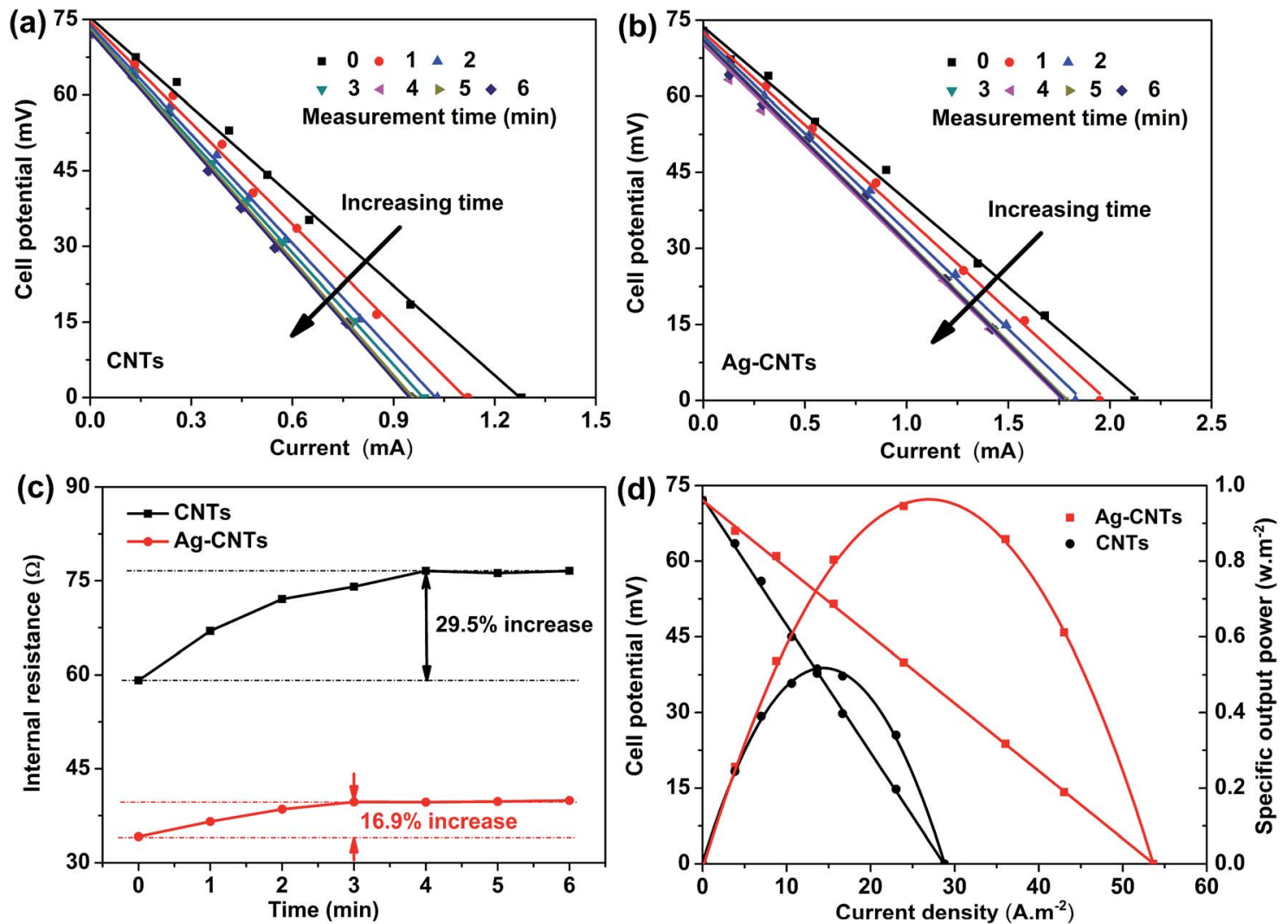

Fig. 4 Cell potential versus current for (a) CNTs and (b) Ag-CNTs electrodes. (c) Internal resistance versus time and (d) plots of cell potential and specific output power versus current density at the steady state. 

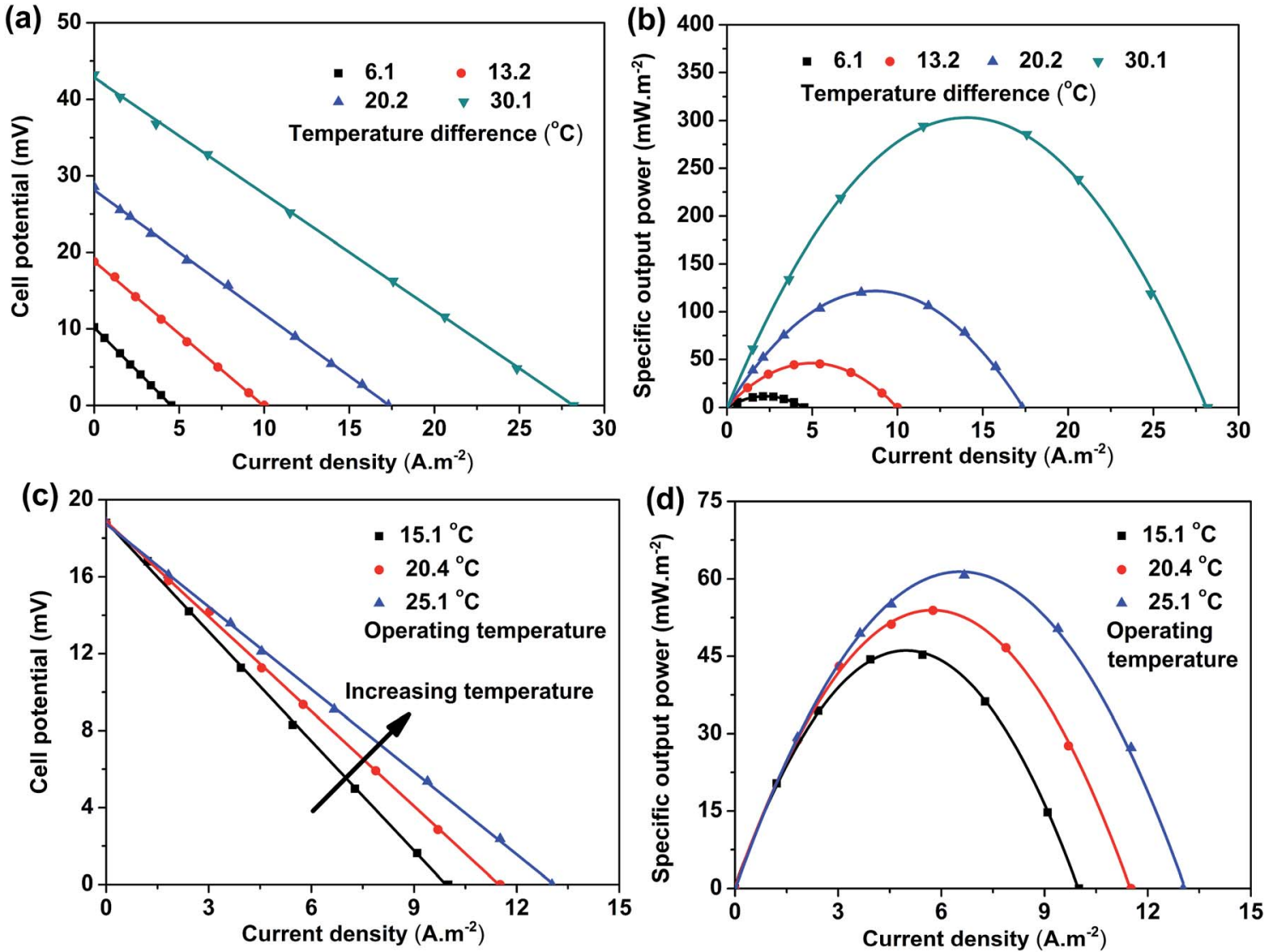

Fig. 5 Effects of temperature difference on the dependence of (a) cell potential and (b) specific output power on current density and effects of operating temperature on the dependence of (c) cell potential and (d) specific output power on current density.

Fig. 4a and b. With an increase in time, the internal resistance (i.e., the slope of the $U-I$ curves) of the TECs for both electrodes improved and the Ag-CNTs electrode reached the equilibrium state after $3 \mathrm{~min}$, which is less time than that of the pristine CNTs electrode (4 min). During the continuous operation of the cells, buildup of the concentration gradient occurs, especially at the cold side of the TECs. ${ }^{2,9}$ Therefore, the mass transport overpotential should be considered in practical applications. The mass transport overpotential can be estimated by measuring the time dependence of the internal resistance of the TEC. The AgCNTs hybrid electrode reached the steady state with the internal resistance of $39.93 \Omega$ (Fig. 4c), which is lower than that of the pristine CNTs electrode, due to its lower thermal resistance ${ }^{2,9}$ and more reaction activation sites. ${ }^{10}$ As shown in Fig. $4 \mathrm{~d}$, the Ag-CNTs electrode generated a $J_{\mathrm{SC}}$ of $53.6 \mathrm{~A} \mathrm{~m}^{-2}$ and $P_{\mathrm{MAX}}$ of $0.967 \mathrm{~W} \mathrm{~m}^{-2}$, corresponding to a normalized current density $\left(J_{\mathrm{SC}} \Delta T^{-1}\right)$ of $1.07 \mathrm{~A}$ $\mathrm{m}^{-2} \mathrm{~K}^{-1}$ and normalized specific power density $\left(P_{\mathrm{MAX}} \Delta T^{-2}\right)$ of $0.387 \mathrm{~mW} \mathrm{~m}^{-2} \mathrm{~K}^{2}$, respectively, which are $85.7 \%$ higher than that for the pristine CNTs electrode and contribute to better conductivity and lower thermal resistance at the electrode/substrate junctions. ${ }^{2,6}$

The energy conversion efficiency $(\eta)$ can be calculated using the following formula: ${ }^{2,10}$

$$
\eta=\frac{0.25 V_{\mathrm{oc}} I_{\mathrm{sc}}}{A k(\Delta T / d)}
$$

where, $V_{\mathrm{oc}}$ represents the open-circuit potential, $I_{\mathrm{sc}}$ is the shortcircuit current, $A$ is the cross-sectional area of the electrode, $k$ represents the thermal conductivity of the redox couple, and $\Delta T$ and $d$ are the temperature difference and distance between the test electrodes, respectively. The relative energy conversion efficiency $\left(\eta_{\mathrm{r}}\right)$ can be described as $\eta_{\mathrm{r}}=\eta /\left(\Delta T / T_{\mathrm{H}}\right)$, where, $T_{\mathrm{H}}$ represents the temperature of the hot side. $\eta_{\mathrm{r}}$ for the pristine CNTs electrode and Ag-CNTs hybrid electrode is $0.51 \%$ and $0.96 \%$, respectively.

The open-circuit potential is mainly determined by the temperature difference $(\Delta T)$ between the test electrodes; however, the relation between the maximum output power $\left(P_{\mathrm{MAX}}\right)$ and the temperature difference is more complicated. ${ }^{3}$ Taking the Ag-CNTs hybrid electrode as an example (Fig. 5a), with an increase in temperature difference, the open-circuit potential increases from $10.2 \mathrm{mV}$ for $\Delta T=6.1{ }^{\circ} \mathrm{C}$ to $43.21 \mathrm{mV}$ for $\Delta T=30.1^{\circ} \mathrm{C}$, resulting in an enhancement in $P_{\mathrm{MAX}}$ from $11.5 \mathrm{~mW} \mathrm{~m}^{-2}$ for $\Delta T=6.1^{\circ} \mathrm{C}$ to $304.2 \mathrm{~mW} \mathrm{~m}^{-2}$ for $\Delta T=30.1^{\circ} \mathrm{C}$ (Fig. 5b). The internal resistance of the cell decreases with an increase in temperature difference (see SI-5 in ESI $\dagger$ ) and the $P_{\text {MAX }}$ increases quadratically with the temperature difference (see SI-6 in ESI $\dagger$ ). As shown in Fig. 5c, under the same temperature difference $\left(13.2^{\circ} \mathrm{C}\right)$, the internal resistance of the cell decreased (also see SI-7 in ESI $\dagger$ ) with the increase in operating temperature (the average temperature of the hot and cold electrodes). The decrease in the internal resistance benefits the 
ion transport and diffusion between the test electrodes, ${ }^{3}$ leading to an improvement in $J_{\mathrm{SC}}$ of $13.0 \mathrm{~A} \mathrm{~m}^{-2}$ and $P_{\mathrm{MAX}}$ of $61.2 \mathrm{~mW}$ $\mathrm{m}^{-2}$ at a high operating temperature of $25.1{ }^{\circ} \mathrm{C}$, which are higher than that at an operating temperature of $15.1{ }^{\circ} \mathrm{C}$.

To obtain a higher output power, two identical cells were connected in series (see SI-8 in ESI $\dagger$ ). The two cell system generated a voltage of $140.2 \mathrm{mV}$ at the temperature difference of $50{ }^{\circ} \mathrm{C}$, which is approximately twice of that for the single cell. Meanwhile, the internal resistance of the cell was doubled as well. According to the relation $P=U^{2} / R$, the output power of the two cell system is twice that of the individual cell. The $P_{\mathrm{MAX}}$ of the Ag-CNT hybrid electrode is $1.93 \mathrm{~W} \mathrm{~m}^{-2}$.

\section{Conclusions}

In summary, Ag-CNT hybrid electrodes were prepared using two simple and effective steps, which involved the direct growth of CNTs on stainless steel substrates without any external catalyst, followed by decorating CNTs with Ag NPs. The asprepared electrodes were characterized via SEM, X-ray diffraction, Raman spectroscopy and X-ray photoelectron spectroscopy. The TEC performances of the hybrid Ag-CNT electrodes were improved significantly compared to that of the pristine CNT electrode, which is attributed to their better electrical and thermal conductivities, as well as more activation sites. This study demonstrates that decorating CNT electrodes with Ag NPs is effective to enhance the TEC performances of the CNT electrode, which is promising for heat energy harvesting by CNTbased electrodes.

\section{Acknowledgements}

This work was financially supported by National Science Foundation of China (No. 51302193, 61620106006, 11274244), Innovation and Entrepreneurship Training Program of Wenzhou University (No. DC2015049).

\section{Notes and references}

1 S. Chu and A. Majumdar, Nature, 2012, 488, 294-303.

2 R. C. Hu, B. A. Cola, N. Haram, J. N. Barisci, S. Lee, S. Stoughton, G. Wallace, C. Too, M. Thomas, A. Gestos, M. E. D. Cruz, J. P. Ferraris, A. A. Zakhidov and R. H. Baughman, Nano Lett., 2010, 10, 838-846.

3 T. J. Kang, S. L. Fang, M. E. Kozlov, C. S. Haines, N. Li, Y. H. Kim, Y. S. Chen and R. H. Baughman, Adv. Funct. Mater., 2012, 22, 477-489.

4 T. I. Quickenden and Y. Mua, J. Electrochem. Soc., 1995, 142, 3985.

5 W. J. Qian, M. X. Cao, F. Xie and C. K. Dong, Nano-Micro Lett., 2016, 8, 240-246.

6 W. J. Qian, M. J. Li, L. H. Chen, J. H. Zhang and C. K. Dong, RSC Adv., 2015, 5, 97982-97987.

7 M. S. Romano, N. Li, D. Antiohos, J. M. Razal, A. Nattestad, S. Beirne, S. L. Fang, Y. S. Chen, R. Jalili, G. G. Wallace, R. Baughman and J. Chen, Adv. Mater., 2013, 25, 6602-6606.
8 H. D. Yang, L. T. Tufa, K. M. Bae and T. J. Kang, Carbon, 2015, 86, 118-123.

9 H. Im, H. G. Moon, J. S. Lee, I. Y. Chung, T. J. Kang and Y. H. Kim, Nano Res., 2014, 7, 443-452.

10 H. Im, T. Kim, H. Song, J. Choi, J. S. Park, R. Ovalle-Robles, H. D. Yang, K. D. Kihm, R. H. Baughman, H. H. Lee, T. J. Kang and Y. H. Kim, Nat. Commun., 2016, 7, 10600.

11 J. Chen, A. I. Minett, Y. Liu, C. Lynam, P. Sherrell, C. Y. Wang and G. G. Wallace, Adv. Mater., 2008, 20, 566-570.

12 S. Talapatra, S. Kar, S. K. Pal, R. Vajtai, L. Ci, P. Victor, M. M. Shaijumon, S. Kaur, O. Nalamasu and P. M. Ajayan, Nat. Nanotechnol., 2006, 1, 112-116.

13 C. Masarapu and B. Q. Wei, Langmuir, 2007, 23, 9046-9049. 14 S. W. Pattinson, B. Viswanath, D. N. Zakharov, J. J. Li, E. A. Stach and A. J. Hart, Chem. Mater., 2015, 27, 932-937. 15 R. X. Dong, C. T. Liu, K. C. Huang, W. Y. Chiu, K. C. Ho and J. J. Lin, ACS Appl. Mater. Interfaces, 2012, 4, 1449-1455.

16 G. Y. Gao, D. J. Guo, C. Wang and H. L. Li, Electrochem. Commun., 2007, 9, 1582-1586.

17 D. J. Guo and H. L. Li, Carbon, 2005, 43, 1259-1264.

18 N. Jha and S. Ramaprabhu, J. Appl. Phys., 2009, 106, 084317.

19 A. R. Boccaccini, J. Cho, J. A. Roether, B. J. C. Thomas, E. J. Minay and M. S. P. Shaffer, Carbon, 2006, 44, 3149-3160. 20 F. Hasche, M. Oezaslan and P. Strasser, Phys. Chem. Chem. Phys., 2010, 12, 15251-15258.

21 A. K. De, D. C. Murdock, M. C. Mataya, J. G. Speer and D. K. Matlock, Scr. Mater., 2004, 50, 1445-1449.

22 F. Xin and L. Li, Composites, Part A, 2011, 42, 961-967.

23 S. B. Fagan, A. G. S. Filho, J. O. G. Lima, J. M. Filho, O. P. Ferreira, I. O. Mazali, O. L. Alves and M. S. Dresselhaus, Nano Lett., 2004, 4, 1285-1288.

24 M. S. Dresselhaus, G. Dresselhaus, A. Jorio, A. G. Souza Filho and R. Saito, Carbon, 2002, 40, 2043-2061.

25 R. Gusain, H. P. Mungse, N. Kumar, T. R. Ravindran, R. Pandian, H. Sugimurac and O. P. Khatri, J. Mater. Chem. A, 2016, 4, 926-937.

26 S. G. Greculeasa, P. Palade, G. Schinteie, G. A. Lungu, C. Porosnicu, I. Jepu, C. P. Lungu and V. Kuncser, J. Nucl. Mater., 2016, 481, 73-80.

27 M. S. Jee, H. S. Jeon, C. Kim, H. Lee, J. H. Koh, J. Cho, B. K. Min and Y. J. Hwang, Appl. Catal., B, 2016, 180, 372378.

28 S. H. Lee, C. C. Teng, C. M. Ma and I. Wang, J. Colloid Interface Sci., 2011, 364, 1-9.

29 Y. Shi, Z. L. Liu, B. Zhao, Y. J. Sun, F. G. Xu, Y. Zhang, Z. W. Wen, H. B. Yang and Z. Li, J. Electroanal. Chem., 2011, 656, 29-33.

30 G. W. Yang, G. Y. Gao, C. Wang, C. L. Xu and H. L. Li, Carbon, 2008, 46, 747-752.

31 L. F. Chen, H. Q. Xie and W. Yu, J. Mater. Sci., 2012, 47, 55905595.

32 A. Gunawan, C. H. Lin, D. A. Buttry, V. Mujica, R. A. Taylor, R. S. Prasher and P. E. Phelan, Nanoscale Microscale Thermophys. Eng., 2013, 17, 304-323. 